\title{
Initial-rupture fault, main-shock fault, and aftershock faults: Fault geometry and bends inferred from centroid moment tensor inversion of the 2005 west off Fukuoka prefecture earthquake
}

\author{
Yoshihiro Ito, Kazushige Obara, Tetsuya Takeda, Katsuhiko Shiomi, Takumi Matsumoto, Shoji Sekiguchi, and Sadaki Hori \\ National Research Institute for Earth Science and Disaster Prevention, 3-1, Tennodai, Tsukuba, Ibaraki, 305-0006, Japan
}

(Received August 10, 2005; Revised November 12, 2005; Accepted November 21, 2005; Online published January 27, 2006)

\begin{abstract}
The 2005 west off Fukuoka prefecture earthquake $\left(M_{\mathrm{JMA}}=7.0\right)$ occurred on March 20, 2005 in northwest Kyusyu, Japan. The fault geometry and rupture propagation of the main shock are investigated by applying the centroid moment tensor (CMT) inversion method to densely-distributed broadband seismic network data. An accurate distribution of small aftershocks is also examined by a double-difference method. The source fault of the main shock whose moment magnitude was 6.6 had a strike of $123^{\circ}$, and the rupture propagated in the southeast direction. We obtain forty-four CMT solutions of the main shock and aftershocks with a moment magnitude greater than 3.5. For the main shock, the fault strike estimated using $P$-wave first-motion polarities differs from that of the moment tensor solution by $13^{\circ}$ in the counterclockwise direction. Some aftershocks with a moment tensor solution similar to the focal mechanism of the main shock derived from the $P$-wave first motions are distributed north of the epicenter of the main shock. The largest aftershock with a strike of $8^{\circ}$ in the clockwise direction, which differs from that of the CMT solution of the main shock, was located south of the main shock. These changes in the fault strike play an important role in the initiation and termination of the rupture process of the main shock.
\end{abstract}

Key words: Centroid moment tensor solution, doublet, rupture propagation, fault bend.

\section{Introduction}

A large earthquake occurred west off Fukuoka prefecture, Kyushu, Japan, at 1:53 universal time (UT) on March 20, 2005 (Fig. 1). This earthquake, referred to as the 2005 west off Fukuoka prefecture earthquake, strongly shook Fukuoka city with a maximum seismic intensity of less than 6 according to the Japan Meteorological Agency (JMA) scale. The hypocenter of the main shock with a local body-wave magnitude $\left(M_{\mathrm{JMA}}\right)$ of 7.0 was located at the northwestern extent of the Kego fault, which passes through the metropolitan area of Fukuoka city, at a depth of $9.8 \mathrm{~km}$ (JMA, 2005). The focal area is located on the Eurasian plate overriding the Philippine Sea Plate, which subducts northwest at a rate of about $4 \mathrm{~cm} / \mathrm{yr}$ (Seno et al., 1993).

Waveform inversion is a powerful tool for calculating centroid locations and moment tensor solutions simultaneously despite the presence of limited seismic stations just above and around the focal area (e.g., Dreger and Helmberger, 1990; Ito et al., 2004, 2005). Matsumoto et al. (2006) calculated the moment tensor solutions for many small aftershocks with magnitudes less than 4 ; these aftershocks occurred in the focal area of the 2005 west off Fukuoka prefecture earthquake. Further, the relationship between the distribution of moment tensor solutions and the coseismic-slip area of the main shock was discussed in de-

Copyright (c) The Society of Geomagnetism and Earth, Planetary and Space Sciences (SGEPSS); The Seismological Society of Japan; The Volcanological Society of Japan; The Geodetic Society of Japan; The Japanese Society for Planetary Sciences; TERRAPUB tail. In their analysis, moment tensor solutions and centroid depths were calculated by using only the waveforms observed at three stations, and the epicenters determined by JMA were used as centroid epicenters.

In this study, we employ a centroid moment tensor inversion method to calculate the centroid location, time and moment tensor solutions of the main shock and aftershocks of the 2005 west off Fukuoka prefecture earthquake. The magnitudes of the aftershocks are greater than 4, mainly. The results are used to estimate the distribution of the source fault in and around the focal area. We also estimate the direction of rupture propagation of the main shock. These estimations are based on data obtained by a "denselydistributed broadband seismic network" composed of tiltmeter and broadband seismometer networks. These network were established by the National Research Institute for Earth Science and Disaster Prevention (NIED). Finally, we discuss the initiation and termination of the rupture of the main shock controlled by fault bends.

\section{Centroid Moment Tensor Inversion Method}

We adopted the centroid moment tensor (CMT) inversion method (Ito et al., 2005) to calculate the moment tensor solutions, centroid locations, and centroid time. In this method, the centroid locations and times with maximum variance reduction $(V R)$ were calculated using a grid-search algorithm. The moment tensor solution at each grid was calculated by the waveform inversion approach using the least square method (e.g., Dreger and Helmberger, 1990; Fukuyama et al., 1998). Spatial and temporal grid intervals 
Table 1. Estimated source parameters of the main shock and the largest aftershock.

\begin{tabular}{cccccccc}
\hline Centroid time (UT) & Latitude & Longitude & Depth & Strike & Dip & Rake & Moment \\
\hline $2005 / 03 / 20,01: 53: 48$ & $33.74^{\circ} \mathrm{N}$ & $130.18^{\circ} \mathrm{E}$ & $10 \mathrm{~km}$ & $123^{\circ}$ & $86^{\circ}$ & $-4.3^{\circ}$ & $8.4 \times 10^{18} \mathrm{Nm}$ \\
$2005 / 04 / 19,21: 11: 29$ & $33.67^{\circ} \mathrm{N}$ & $130.26^{\circ} \mathrm{E}$ & $11 \mathrm{~km}$ & $131^{\circ}$ & $85^{\circ}$ & $-17.2^{\circ}$ & $1.6 \times 10^{18} \mathrm{Nm}$ \\
\hline
\end{tabular}

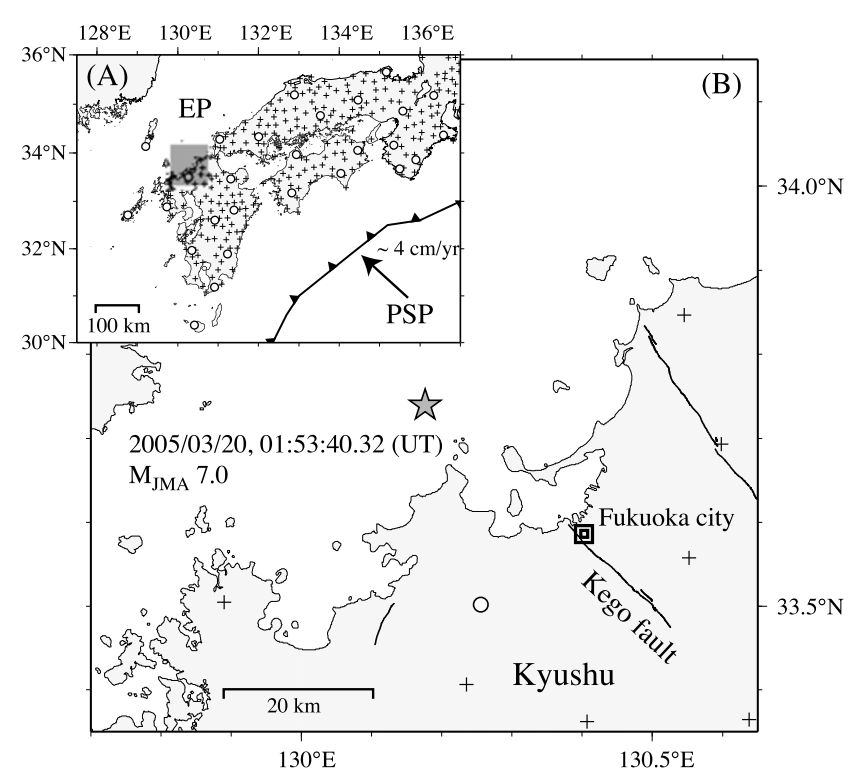

Fig. 1. Tectonic setting, seismic networks, and epicenter of the main shock. (A) Tectonic setting and seismic station distribution. PSP and EP represent the Philippine Sea plate and the Eurasian plate, respectively. Circles and plus symbols indicate the NIED F-net and Hi-net stations. The solid line with triangles indicates the Nankai trough. Relative motion between the Philippine Sea plate and the Eurasian plate (Seno et al., 1993) is indicated by the solid arrow. (B) Epicenter of the main shock and active faults. The star indicates the epicenter of the main shock. The active fault distribution is based on the results of Nakata and Imaizumi (2002). The double-square indicates the center of Fukuoka city.

were set to be $0.01^{\circ}$ horizontally, $1 \mathrm{~km}$ in depth, and $1 \mathrm{~s}$, where the depth of the shallowest grid was $3 \mathrm{~km}$. VR was defined as follows:

$$
V R[\%]=\sum_{i} \int\left(1-\frac{\left(\left(s_{i}(t)-o_{i}(t)\right)^{2}\right.}{\left(o_{i}(t)\right)^{2}}\right) d t \times 100,
$$

where $s_{i}(t)$ and $o_{i}(t)$ were synthetic and observed waveforms at station $i$, respectively. $V R$ is $100 \%$ when the synthetic waveforms completely agree with the observed ones. If the synthetic waveforms are off by half a cycle, $V R$ assumes a negative value. We used the same velocity and seismic attenuation structure as that adopted for the routine NIED F-net moment tensor approach (Fukuyama et al., 1998) to calculate Greenfs functions.

Further, we used a combined seismic network of broadband seismometers and tiltmeters as the densely-distributed broadband seismic network. The NIED F-net and Hi-net stations in Japan are located at intervals of $100 \mathrm{~km}$ and $20 \mathrm{~km}$, respectively (Okada et al., 2004; Obara et al., 2005). Three-component broadband seismometers were installed at each F-net station. Two-horizontal-component high-sensitivity borehole accelerometers were installed at each Hi-net station in addition to a three-component highsensitivity velocity seismometer. The accelerometers were used as tiltmeters, which are useful in detecting and analyzing low-frequency earthquakes (Obara and Ito, 2005). The velocity and acceleration seismograms observed using the F-net broadband seismometers and Hi-net tiltmeters were integrated to displacement and used as observed waveforms in the CMT inversion method. The waveform data were filtered with a passband of $0.02-0.05 \mathrm{~Hz}$ and decimated to a sampling rate of $1 \mathrm{~Hz}$.

Between March 20 and June 3, 2005, the JMA catalog lists 109 earthquakes whose JMA magnitudes exceed 3.5. The waveform data with a low signal-to-noise ratio due to contamination by other earthquakes or highly artificial noise in the same time window were excluded from the listed events. We applied the CMT inversion method to the remaining 44 earthquakes whose waveform data were observed at more than 15 stations. We used hypocentral parameters from the JMA catalog as the initial centroid location and time for the CMT inversion.

\section{Moment Tensor Solutions}

Forty-four CMT solutions were calculated by the CMT inversion method. In these results, the $V R s$ were in the range of $52-94 \%$, and in $70 \%$ of the results, they exceeded $80 \%$. Figure 2 shows an example of a calculated moment tensor solution and the observed and synthetic waveforms of a small aftershock with a moment magnitude of 3.9 and a $V R$ of $89.5 \%$. The observed and synthetic waveforms were in good agreement. In order to assess the validity of the moment tensor solution, we compared the moment tensor solution with the $P$-wave first motion polarities observed at the Hi-net stations using the high-sensitivity seismometers. The moment tensor solution was consistent with the distribution of the $P$-wave first motion polarities (Fig. 2).

For the main shock and the largest aftershock, the calculated fault-orientation parameters and moment magnitudes are listed in Table 1. The fault strike of the largest aftershock differed from that of the main shock by $8^{\circ}$ in the clockwise direction. The centroid of the largest aftershock was located south of that of the main shock.

Figure 3 shows the horizontal distribution and vertical cross section of the moment tensor solutions. It should be note that a centroid location, which is a release point of seismic energy mainly, is not always the same as the hypocenter, which was determined by first arrival data as a rupture initiation point. Almost all the moment tensor solutions were those of strike-slip faulting. The strike of the horizontal distribution of the moment tensor solutions was aligned in the northwest direction. Most solutions tended to concentrate at the northwestern and southeastern parts of the aftershock area. In the central part, the main shock 
2005/03/21, 06:17:03

Mw 3.9 VR $89.5 \%$

$130.19^{\circ} \mathrm{E} 33.72^{\circ} \mathrm{N}$

Depth $6 \mathrm{~km}$

- Obs.

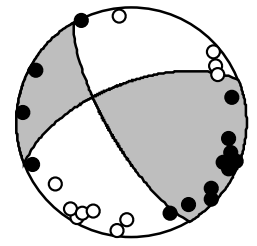

$$
\begin{gathered}
120 \mathrm{~s} \\
\text { Tangential Radial Vertical }
\end{gathered}
$$

YSI F-net

Delta: $296 \mathrm{~km}$

Azimuth: $55^{\circ}$

Max. amp: $4.37 \times 10^{-7} \mathrm{~m}$

OOZ Hi-net

Delta: $223 \mathrm{~km}$

Azimuth: $93^{\circ}$

Max. amp: 2.37 x $10^{-7} \mathrm{~m}$

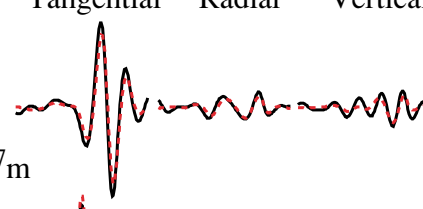

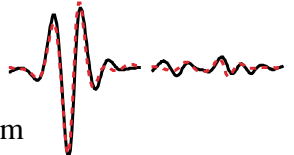

Delta: $199 \mathrm{~km}$

Azimuth: $138^{\circ}$

Max. amp: $4.51 \times 10^{-7} \mathrm{~m}$

ASK Hi-net

Delta: $163 \mathrm{~km}$

Azimuth: $167^{\circ}$

Max. amp: $5.18 \times 10^{-7} \mathrm{~m}$

Max. amp: $4.38 \times 10^{-7} \mathrm{~m}$
Delta: $102 \mathrm{~km}$

Azimuth: $205^{\circ}$

Max. amp: $4.12 \times 10^{-7} \mathrm{~m}$

IZH F-net

Delta: $101 \mathrm{~km}$

Azimuth: $296^{\circ}$
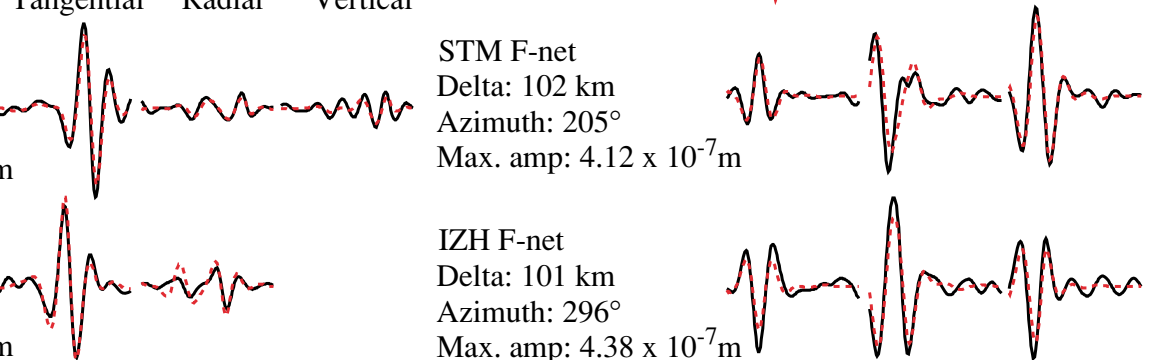

Fig. 2. Example of obtained moment tensor solutions and synthetic and observed waveforms. The focal sphere projected to the lower hemisphere shows the moment tensor solution. Solid and open circles indicate the dilatational and compressional $P$-wave first polarities observed at the NIED Hi-net stations. Solid and red broken lines indicate the observed and synthetic waveforms, respectively.

Table 2. Four rupture cases and the obtained variance reductions.

\begin{tabular}{cc}
\hline Rupture & Variance reduction $(\%)$ \\
\hline Case 1 (from A to $\mathrm{A}^{\prime}$ ) & 85.1 \\
Case 2 (from A ${ }^{\prime}$ to A) & 68.5 \\
Case 3 (from B to B') & 67.8 \\
Case 4 (from B' to B) & 68.3 \\
\hline
\end{tabular}

was located at a depth of $10 \mathrm{~km}$, and some aftershocks were observed at a shallower part near the main shock.

\section{Source Fault and Rupture Propagation of the Main Shock}

In order to determine the source fault and direction of rupture propagation of the main shock, we applied the doublet line source method (Tsuboi and Fukao, 1996; Tsuboi et al., 1998) to the observed waveforms of the main shock. In this method, the CMT solution was regarded as a doublet composed of two point sources. The focal mechanism of the two point sources was the same as that of the main shock, and they possessed half the seismic moment of the CMT solution obtained by the CMT inversion method. The point sources of a doublet were located at both ends of the fault strike estimated from one of the nodal planes at the centroid of the main shock. Figure 4(A) shows the assumed doublets and stations used in this approach. Two doublet pairs and two rupture propagation cases for each doublet were examined. The fault length of the main shock empirically varies between 20 and $30 \mathrm{~km}$ when the moment magnitude is 6.6. By trial and error, we investigated some cases of fault length and rupture velocities and estimated their values as $18 \mathrm{~km}$ and $3 \mathrm{~km} / \mathrm{s}$, respectively. All the point sources were located $9 \mathrm{~km}$ from the centroid of the main shock. At one of the point sources of the two doublets, the ruptures commenced $3 \mathrm{~s}$ before and after the centroid time estimated by the CMT inversion. We assessed the $V R$ val-

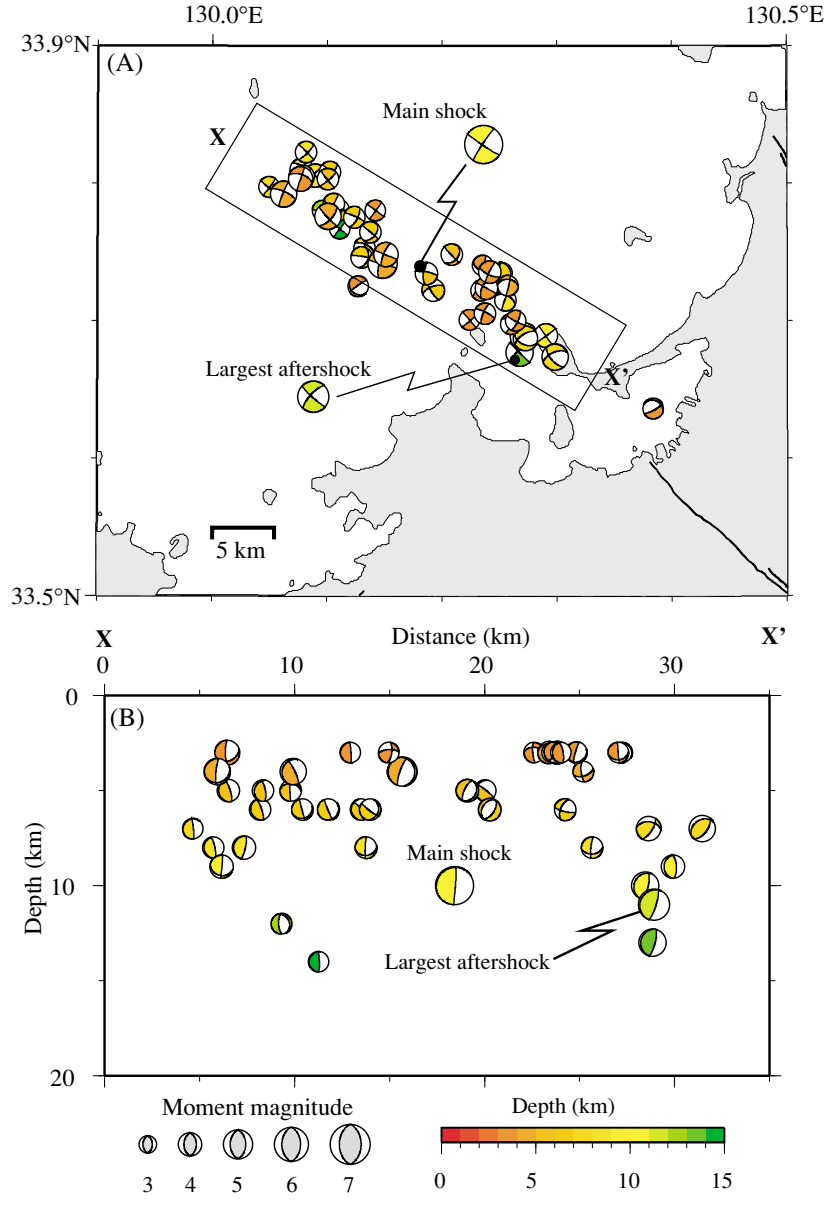

Fig. 3. Distribution of the centroid moment tensor solution. (A) Horizontal distribution. (B) Vertical cross section along $\mathrm{X}-\mathrm{X}^{\prime}$.

ues in four cases by comparing the observed and synthetic waveforms obtained from 15 NIED F-net stations. We also alternatively determined the most suitable source fault and rupture propagation direction with the maximum $V R$. 


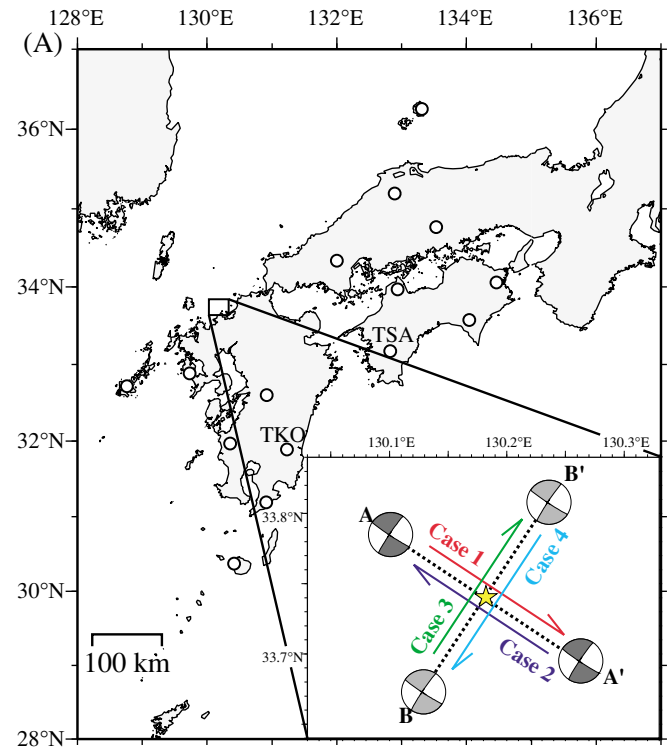

(B) Station: TSA Delta: $253 \mathrm{~km}$ Azimuth: $103^{\circ}$

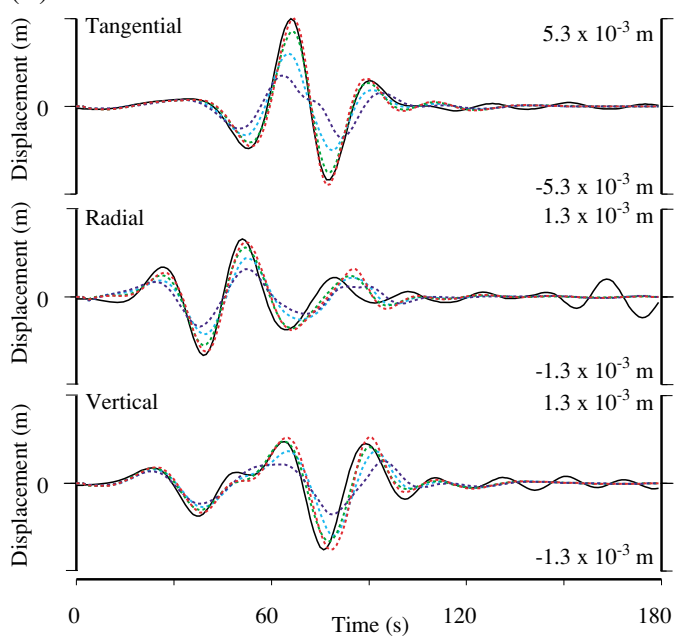

(C) Station: TKO Delta: $227 \mathrm{~km}$ Azimuth: $154^{\circ}$
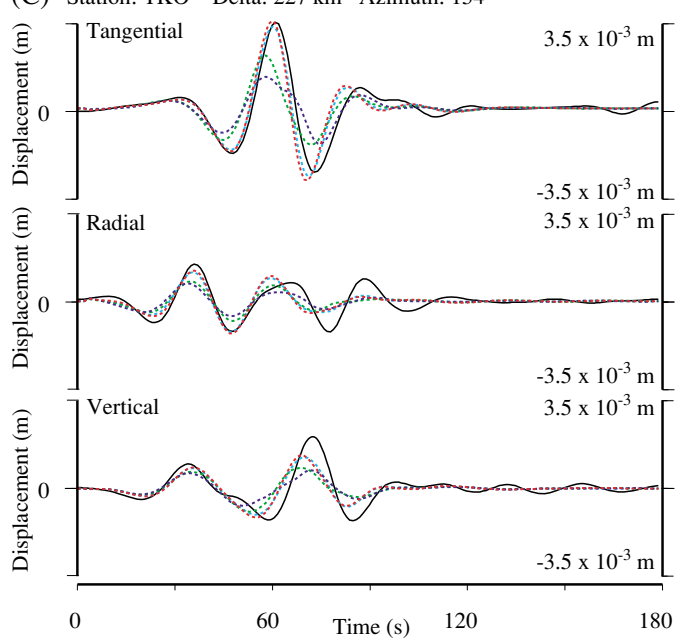

Fig. 4. Doublet line source distribution and comparison between the observed and synthetic waveforms. (A) Distribution of used stations and doublet point sources. Two doublet pairs are indicated as focal mechanisms in dark and light gray. Four cases of rupture propagations are indicated by the red, blue, green, and light blue arrows. The star indicates the centroid location of the main shock. (B) (C) Example of waveform fitting in doublet line source modeling. Black lines represent observed waveforms. Four colored broken lines show synthetic waveforms. The red, blue, green, and light blue lines indicate cases 1-4 shown in (A), respectively.
(A)

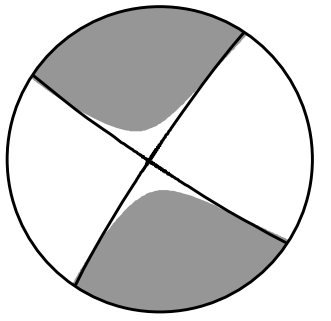

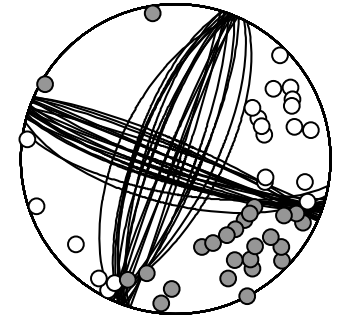

(B)
Fig. 5. Two faulting mechanisms of the main shock. (A) Moment tensor solution. (B) Focal mechanism derived using $P$-wave first motions. Some possible nodal planes are shown. Solid and open circles indicate dilatational and compressional $P$-wave first polarities observed at the NIED Hi-net stations.

Table 2 shows the results of the doublet line source method. Case 1 showed the maximum $V R$ of $85.1 \%$. Therefore, the strike of the fault plane was along the NW-SE direction, and the rupture propagated in the southeast direction. Figure 4(B) and 4(C) show examples of waveform fitting at two different stations for the four cases. Both stations were in azimuths different from the focal areas. The synthetic waveforms of case 1 were the most suitable in terms of amplitude and phase.

\section{Initial-Rupture Fault}

The general features of the rupture of the main shock were that it propagated in the southeast direction and the source fault had a fault strike of $123^{\circ}$. A moment tensor catalog described the similarity between the fault strikes of $122^{\circ}$ and $124^{\circ}$ reported by the Harvard Seismology CMT catalog and the USGS fast moment tensor solutions, respectively. Matsumoto et al. (2006) recalculated the moment tensor solutions of the main shock using the NIED F-net waveform data and obtained the fault strike of $122^{\circ}$, which was the same as our result. Nishimura et al. (2006) obtained the fault model with fault strike of $118^{\circ}$ using the coseismic deformation observed by GPS and InSAR. On the other hand, a fault strike with an average value of $110^{\circ}$ was derived using the $P$-wave first motion polarities of the NIED Hi-net stations. However, a solitary nodal-plane solution was not determined, and the derived fault strike differed from that of the moment tensor solution by $13^{\circ}$ in the counterclockwise direction (Fig. 5).

In order to obtain the fault geometry in detail, we adopted the double-difference method (Waldhauser and Ellsworth, 2000). We relocated 1390 aftershocks that occurred between March 20 and April 30, 2005 with a JMA magnitude greater than 2.0 and compared the centroid locations of all the moment tensor solutions. Figure 6(A) shows the distribution of the relocated aftershocks. We considered one of the nodal planes - obtained by the CMT inversion-with the NW-SE fault strike as the source fault because the seismicity forms a narrow northwest-striking zone in the entire focal area. We also compared the distribution of the source fault with the seismicity shown in Fig. 6(A). It should be emphasized that the fault orientation of some aftershocks occurring near northwest of the epicenter of the main shock exhibits the fault strike of $110^{\circ}$, which is the same as that 
of the focal mechanism derived using the $P$-wave first motion polarities for the main shock. Therefore, the rupture of the main shock was initiated on the fault strike of $110^{\circ}$. We considered the fault patch of the initial rupture, which had a different strike from the fault of the main rupture, as the "initial-rupture fault."

\section{Discussion}

The moment tensor solution of the main shock was different from the focal mechanism derived using the $P$-wave first motion polarities. The same feature was observed for the 2000 western Tottori earthquake in Japan (Ito, 2005). Hori (2002) reported that some focal mechanisms derived using the $P$-wave first motions differed from the moment tensor solutions because the focal mechanism and moment tensor solution indicated the initial rupture pattern and the average source process of the entire rupture, respectively. An initial-rupture fault whose geometry differs from that of the main-shock fault probably exists near the epicenter in the focal area.

The existence of the initial-rupture fault at the northern part of the main-shock fault and a bend near the epicenter of the main shock can be confirmed based on the following results: (1) the southeastward propagation of the main shock rupture, (2) difference between the fault strike of the moment tensor solution and that of the $P$-wave first motions, and (3) agreement between the fault strike of the aftershocks observed at near northwest of the epicenter of the main shock and that of one of the nodal planes derived using the $P$-wave first motions. The fault strike of the largest aftershock, which occurred south of the main shock, is also different from that of the main-shock fault by $8^{\circ}$ in the clockwise direction.

The accuracy of the moment tensor solutions calculated by NIED F-net moment tensor analysis, which is similar in approach to our CMT inversion method, is less than $10^{\circ}$ (Kubo et al., 2002; Kubo and Fukuyama, 2004). The differences in the fault strikes of the initial-rupture fault, main-shock fault, and the largest fault of the aftershock are probably significant.

For rupture propagation of the main shock, we alternatively detected the fault plane and direction of rupture propagation. However, we were unable to obtain the slip distribution in detail by our doublet line source method. On the other hand, a small coseismic slip of the main shock is distributed in the northern portion of the main fault (Sekiguchi et al., 2006); this suggests a possibility of the rupture propagating northward. The released seismic energy in such a case is lower than that in the case of the rupture propagating southward.

Figure 6(B) shows a possible fault model of the 2005 west off Fukuoka prefecture earthquake. In this model, we describe the rupture process of the main shock as follows. First, the rupture of the main shock began at the initialrupture fault strike of $110^{\circ}$, whose length was determined based on the distribution of aftershocks with a similar fault strike, and propagated southeastward. Next, the main asperity on the main-shock fault with a strike of $123^{\circ}$ ruptured. Finally, the rupture terminated near a bend in the fault strike. The largest aftershock occurred in the south-
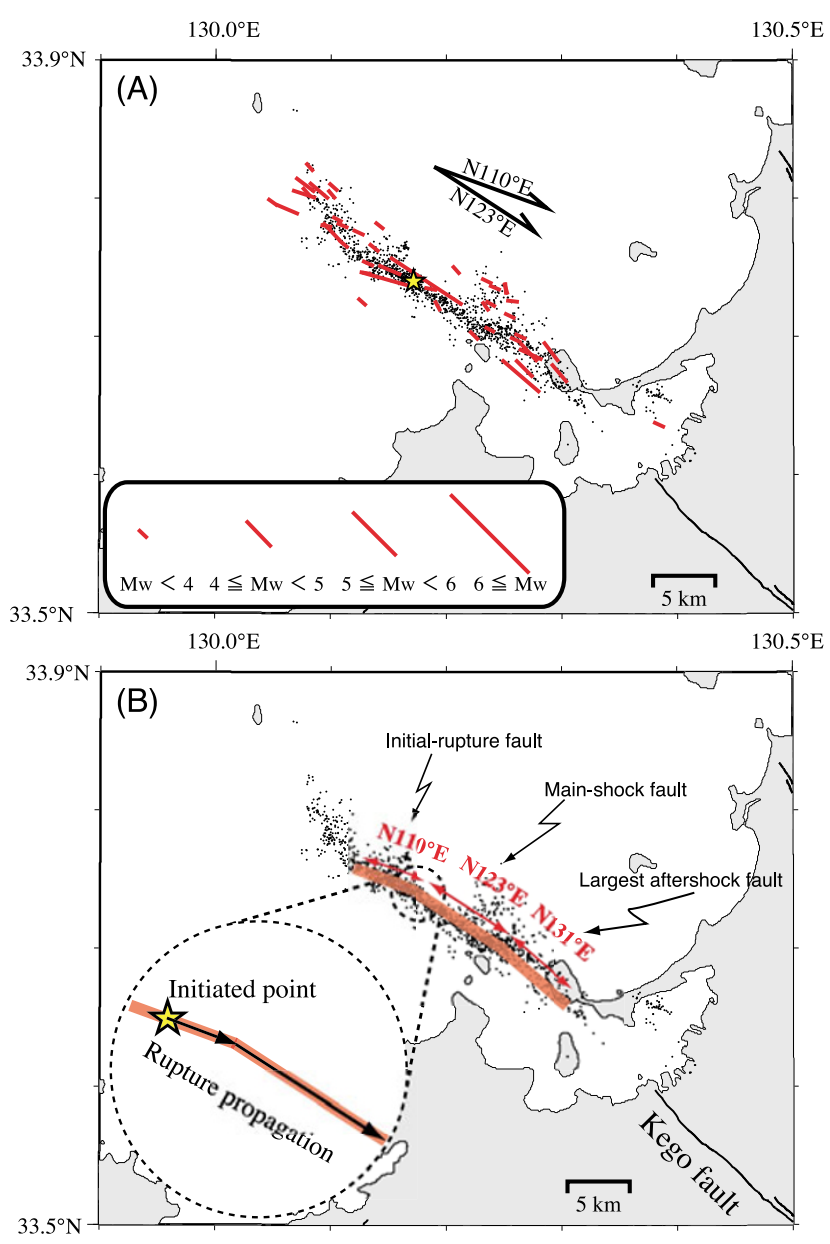

Fig. 6. Source-fault orientation of the main shock and aftershocks. (A) Orientations of fault strike. Only NW-SE fault strikes derived by centroid moment tensor inversion are shown. Fault lengths dependent on the moment magnitude are indicated in the legend shown in (A). Two arrows indicate references of the fault strike of the initial-rupture and main-shock faults. The yellow star indicates the epicenter of the main shock recalculated by the double-difference method. (B) Fault model of the 2005 west off Fukuoka prefecture earthquake.

east direction, and the strike of the fault plane located at the northwestern extent of the Kego fault was $131^{\circ}$. King and Nábělek (1985) pointed out that fault bends played an important role in rupture initiation and termination. For the 2005 west off Fukuoka prefecture earthquake, the rupture initiation and termination may be controlled by fault bends extending from the initial-rupture fault to the main-shock fault and those from the main-shock fault to the fault of the largest aftershock, respectively. The detection of fault bends will be important for the estimation of the initiation point of a rupture.

In the northern part of the aftershock area, the fault strikes of the aftershock appeared to be en echelon and were inconsistent with the alignment of the seismicity. Some small echelon faults or spray faults may exist in the northern part of the focal area. These features are similar to those of the north end of the main-shock fault of the 2000 western Tottori earthquake (Fukuyama et al., 2003).

Our simple estimation of the rupture propagation of the main shock showed that the rupture propagated southeastward. Other source process studies also reported a similar 
rupture propagation feature of the main shock (Sekiguchi et al., 2006; Asano and Iwata, 2006). The directivity effect due to the southeastward rupture propagation was also observed (Miyake and Koketsu, 2005). For other aftershocks including the largest aftershock, the source fault and direction of rupture propagation could not be calculated by our approach because the fault sizes might be considerably small. However, this approach enables the selection of a source fault from two nodal planes estimated by the CMT inversion method and quick determination of the direction of rupture propagation for large earthquakes.

\section{Conclusions}

By using a densely-distributed broadband seismometer network of the NIED, we applied the centroid moment tensor inversion method to the main shock and aftershocks of the 2005 west off Fukuoka prefecture earthquake. Many moment tensor solutions with a moment magnitude between 3.5 and 6.6 were calculated to obtain the distribution of the source faults in the focal area. An accurate distribution of small aftershocks was obtained by the doubledifference method. Based on the fault geometry and rupture propagation determined by the doublet line source approach, source-fault distribution for the aftershocks, and precise small-aftershock distribution, the following results were obtained. The rupture of the main shock was initiated on the initial-rupture fault with a strike of $110^{\circ}$. It propagated in the southeast direction, and the seismic wave energy was released at the main-shock fault with a strike of $123^{\circ}$. The rupture was arrested at the southeast end, where a bend occurred in the fault. Finally, the largest aftershock with a strike of $131^{\circ}$ occurred at the northwestern extent of the Kego fault.

Acknowledgments. The Generic mapping tools (GMT) software (Wessel and Smith, 1991) was used to prepare the figures. The Harvard Seismology CMT catalog and the USGS fast moment tensor solution data were used. We used the digital data of an active fault; the data was edited by Nakata and Imaizumi (2002). The article was significantly improved through constructive reviews by Dr. M. Kosuga and an anonymous reviewer. This work was conducted under the project "Operation of Seismic Observation Networks" at the National Research Institute for Earth Science and Disaster Prevention.

\section{References}

Asano, K. and T. Iwata, Source process and near-source ground motions of the 2005 West Off Fukuoka Prefecture earthquake, Earth Planets Space, 58, this issue, 93-98, 2006.

Dreger, D. S. and D. V. Helmberger, Broadband modeling of local earthquakes, Bull. Seismol. Soc. Am., 80, 1162-1179, 1990.

Fukuyama, E., M. Ishida, D. S. Dreger, and H. Kawai, Automated seismic moment tensor determination by using on-line broadband seismic waveforms, J. Seismol. Soc. Japan (Zisin), 51, 149-156, 1998 (in Japanese with English abstract).

Fukuyama, E., W. L. Ellsworth, F. Waldhauser, and A. Kubo, Detailed fault structure of the 2000 western Tottori, Japan, earthquake sequence, Bull. Seismol. Soc. Am., 93, 1468-1478, 2003.

Harvard Seismology CMT catalog, http://www.seismology.harvard.edu/, Harvard University, 2005.
Hori., S., Comparison of earthquake mechanism solutions obtained from first motion analysis with those from waveform analysis, J. Seismol. Soc. Japan (Zisin), 55, 275-284, 2002 (in Japanese with English abstract).

Ito, Y., Mechanisms of aftershock generation, Rep. Nat'l. Res. Inst. Earth Sci. Disas. Prev., 68, 27-89, 2005, (in Japanese with English abstract).

Ito, Y., H. Matsubayashi, H. Kimura, T. Matsumoto, Y. Asano, and S. Sekiguchi, Spatial distribution for moment tensor solutions of the 2003 Tokachi-oki earthquake $\left(M_{\mathrm{JMA}}=8.0\right)$ and aftershocks, Earth Planets Space, 56, 301-306, 2004.

Ito, Y., T. Matsumoto, H. Kimura, H. Matsubayashi, K. Obara, and S. Sekiguchi, Spatial distribution of centroid moment tensor solutions for the 2004 off Kii peninsula earthquakes, Earth Planets Space, 57, 351356, 2005.

Japan Meteorological Agency, The Seismological and Volcanological Bulletin of Japan, Japan Meteorological Agency, Tokyo, 2005.

King, G. and J. Nábělek, Role of fault bends in the initiation and termination of earthquake rupture, Science, 228, 984-985, 1985.

Kubo, A. and E. Fukuyama, Stress fields and fault reactivation angles of the 2000 western Tottori aftershocks and the 2001 northern Hyogo swarm in southwest Japan, Tectonophysics, 378, 223-239, 2004.

Kubo, A., E. Fukuyama, H. Kawai, and K. Nonomura, NIED seismic moment tensor catalogue for regional earthquakes around Japan: quality test and application, Tectonophysics, 356, 23-48, 2002.

Matsumoto, T., Y. Ito, H. Matsubayashi, and S. Sekiguchi, Spatial distribution of F-net moment tensors for the 2005 West Off Fukuoka Prefecture Earthquake determined by the extended method of the NIED F-net routine, Earth Planets Space, 58, this issue, 63-67, 2006.

Miyake, H. and K. Koketsu, Source Process, Strong Motion and Damages, http://www.eri.u-tokyo.ac.jp/topics/fukuoka200503/index-e.html, University of Tokyo, 2005.

Nakata, T. and T. Imaizumi, Digital Active Fault Map of Japan, University of Tokyo press, Tokyo, 2002.

Nishimura, T., S. Fujiwara, M. Murakami, H. Suito, M. Tobita, and H. Yarai, Fault model of the 2005 Fukuoka-ken Seiho-oki earthquake estimated from coseismic deformation observed by GPS and InSAR, Earth Planets Space, 58, this issue, 51-56, 2006.

Obara, K. and Y. Ito, Very low frequency earthquakes excited by the 2004 off the Kii peninsula earthquakes: A dynamic deformation process in the large accretionary prism, Earth Planets Space, 57, 321-326, 2005.

Obara, K., K. Kasahara, S. Hori, and Y. Okada, A densely distributed highsensitivity seismograph network in Japan: Hi-net by National Research Institute for Earth Science and Disaster Prevention, Rev. Sci. Instrum., 76, 021301, 2005

Okada, Y., K. Kasahara, S. Hori, K. Obara, S. Sekiguchi, H. Fujiwara and A. Yamamoto, Recent progress of seismic observation networks in Japan -Hi-net, F-net, K-NET, KiK-net, Earth Planets Space, 56, xvxxviii, 2004.

Sekiguchi, H., S. Aoi, R. Honda, N. Morikawa, T. Kunugi, and H. Fujiwara, Rupture process of the 2005 West Off Fukuoka Prefecture earthquake obtained from strong motion data of K-NET and KiK-net, Earth Planets Space, 58, this issue, 37-43, 2006.

Seno, T., S. Stein, and A. E. Gripp, A model for the motion of the Philippine Sea plate consistent with NUVEL-1 and geological data, J. Geophys. Res., 89, 17941-17948, 1993.

Tsuboi, S. and Y. Fukao, Determination of doublet source parameters by CMT analysis, Seismol. Soc. Jpn. Program Abstr., A21, 1996.

Tsuboi, S., S. Hori, and Y. Fukao, A method of determining the centroid of CMT solution, The 1998 Japan Earth and Planetary Science Joint Meeting, Sc-p004, 1998.

USGS fast moment tensor solutions, http://neic.usgs.gov/neis/FM/, USGS, 2005.

Waldhauser, F. and W. L. Ellsworth, A double-difference earthquake location algorithm: Method and application to the Northern Hayward fault, California, Bull. Seismol. Soc. Am., 90, 1353-1368, 2000.

Wessel, P. and W. H. F. Smith, Free software helps map and display data, Eos Trans. AGU, 72, 445-446, 1991.

Y. Ito (e-mail: yito@bosai.go.jp), K. Obara, T. Takeda, K. Shiomi, T. Matsumoto, S. Sekiguchi, and S. Hori 